\title{
Influence of the particle size on the electrochemical properties of lithium manganese oxide
}

\author{
Chung-Hsin Lu*, Shang-Wei Lin \\ Department of Chemical Engineering, National Taiwan University, Thipei, Taiwan, ROC
}

Received 28 June 2000; accepted 28 December 2000

\begin{abstract}
$\mathrm{LiMn}_{2} \mathrm{O}_{4}$ powders with different particle sizes were obtained by sieving, and the influence of particle size on the electrochemical behavior was examined. With a decrease in particle size, both the specific capacity and the coulomb efficiency become markedly increased. It is suggested that the small particles with large interface area provide more lithium ions for diffusion, leading to the high ionic current and specific capacity. The large interface area between $\mathrm{LiMn}_{2} \mathrm{O}_{4}$ and the liquid electrolyte also increases the opportunity for lithium ions to intercalate back into the host structure. In the cyclic voltammetry test, small $\mathrm{LiMn}_{2} \mathrm{O}_{4}$ particles exhibit the oxidation peaks at higher voltage during the deintercalation process. It is considered that the size of pores among $\mathrm{LiMn}_{2} \mathrm{O}_{4}$ particles is reduced when the particle size is decreased, and the reduced opening results in an increase in the mass-transfer resistance, therefore, more driving force is required to extract lithium ions from the cathode materials. (C) 2001 Elsevier Science B.V. All rights reserved.
\end{abstract}

Keywords: $\mathrm{LiMn}_{2} \mathrm{O}_{4}$ powders; Lithium ion batteries; Particle size

\section{Introduction}

For the utilization of intercalation cathode materials in lithium ion batteries, lithium manganese oxide $\mathrm{LiMn}_{2} \mathrm{O}_{4}$ has been intensively developed on account of its inexpensive material cost, acceptable environmental characteristics, and good safety compared to $\mathrm{LiCoO}_{2}$ [1-3]. On the other hand, $\mathrm{LiMn}_{2} \mathrm{O}_{4}$ has disadvantages, such as relatively low discharge capacity and significant capacity fading upon cycling $[4,5]$. In order to enhance the electrochemical performance of $\mathrm{LiMn}_{2} \mathrm{O}_{4}$, several research groups have developed different processes for synthesizing $\mathrm{LiMn}_{2} \mathrm{O}_{4}$ powders with controlled morphology [6-10]. It was found that the capacity and the cyclability are improved for the powders exhibiting high crystallinity and small particle size.

From the viewpoint of morphology, the particle size of particulate materials is an important factor in affecting their chemical and physical properties. The effects of particle size on the packing of cathode materials consisting of $\mathrm{LiMn}_{2} \mathrm{O}_{4}$ have been reported [11], however, the intrinsic properties of $\mathrm{LiMn}_{2} \mathrm{O}_{4}$ powders with different sizes have not been investigated in detail. In this study, $\mathrm{LiMn}_{2} \mathrm{O}_{4}$ powders were sieved and classified into four sizes, and the relationship between

\footnotetext{
*Corresponding author. Fax: +886-2-3623040.

E-mail address: chlu@ccms.ntu.edu.tw (C.-H. Lu).
}

the particle size and electrochemical performance in lithium ion battery were examined. The cyclic voltammetry measurement was also carried out to explore the extraction/ intercalation behavior of lithium ions.

\section{Experiment}

$\mathrm{LiMn}_{2} \mathrm{O}_{4}$ powders supplied by Merck Co. were used as the cathode material in this study. In order to obtain particles with different sizes, an ultrasonic sieving shaker was used. Three sieves with opening of 25,40 , and $50 \mu \mathrm{m}$ were used. A plate was placed at the bottom to recover the powders smaller than $25 \mu \mathrm{m}$. After the above sieving process, $\mathrm{LiMn}_{2} \mathrm{O}_{4}$ powders with four particle sizes were obtained. Scanning electron microscopy (SEM) was performed to ensure the sieving effect and examine the microstructures of the obtained powders. Size distribution and the average particle size of the sieved powders were analyzed by a particle size analyzer. Electrochemical behavior of the sieved $\mathrm{LiMn}_{2} \mathrm{O}_{4}$ powders was examined in a two-electrode cell. The electrochemical cell contained a $\mathrm{LiMn}_{2} \mathrm{O}_{4}$-based composite as the positive electrode, $\mathrm{Li}$ foil as the negative electrode, and an electrolyte of $1 \mathrm{M} \mathrm{LiPF}_{6}$ in a 1:1 (volume ratio) mixture of EC/DMC. The cell was charged and discharged galvanostatically at $0.2 \mathrm{~mA} / \mathrm{cm}^{2}$ within the 
potential range of 3-4.3 V. For further examining the electrochemical behavior of the powders with different sizes, cyclic voltammetry measurement was carried out in a threeelectrode cell, which consisted of lithium foil as the reference electrode. The three-electrode cell was cycled at a scan rate of $0.5 \mathrm{mV} / \mathrm{s}$ between 3.0 and $4.5 \mathrm{~V}$.

\section{Results and discussion}

The microstructures of the sieved $\mathrm{LiMn}_{2} \mathrm{O}_{4}$ powders were examined by SEM. It is found that the powders with different size are effectively obtained by the sieving process. All powders exhibit a solid form and well-dispersed state. According to the particle size analysis, the average particle sizes $\left(D_{50}\right)$ for four kinds of sieved powders are 19.9, 32.9, 41.9 , and $53.8 \mu \mathrm{m}$, respectively. For the unsieved particles, the average particle size is $30.1 \mu \mathrm{m}$. In comparison with the sieved powders, the unsieved powders have a much broader size distribution. From the above results, it is revealed that the $\mathrm{LiMn}_{2} \mathrm{O}_{4}$ powders with a relatively narrow size distribution and different sizes are successfully achieved. In addition, XRD analysis reveals that all sieved powders have the same XRD pattern.

The charge-discharge curves for the $\mathrm{LiMn}_{2} \mathrm{O}_{4}$ powders with various particle sizes are depicted in Fig. 1. For the particles with average size $\left(D_{50}\right)$ of $19.9,32.9$, and $41.9 \mu \mathrm{m}$, two distinct plateaus clearly appear on both of the charge and discharge curves, indicating the typical electrochemical characteristics of $\mathrm{LiMn}_{2} \mathrm{O}_{4}$. It is reported that the upper plateau region of discharge curve stands for a two-phase

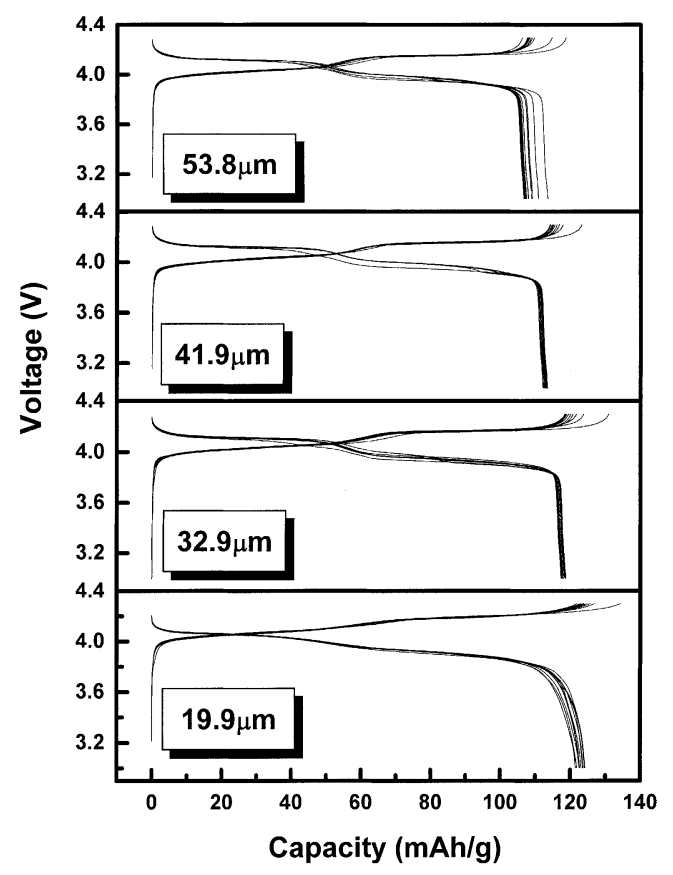

Fig. 1. Charge and discharge curves of $\mathrm{LiMn}_{2} \mathrm{O}_{4}$ powders with different particle sizes at the current density of $0.2 \mathrm{~mA} / \mathrm{cm}^{2}$.

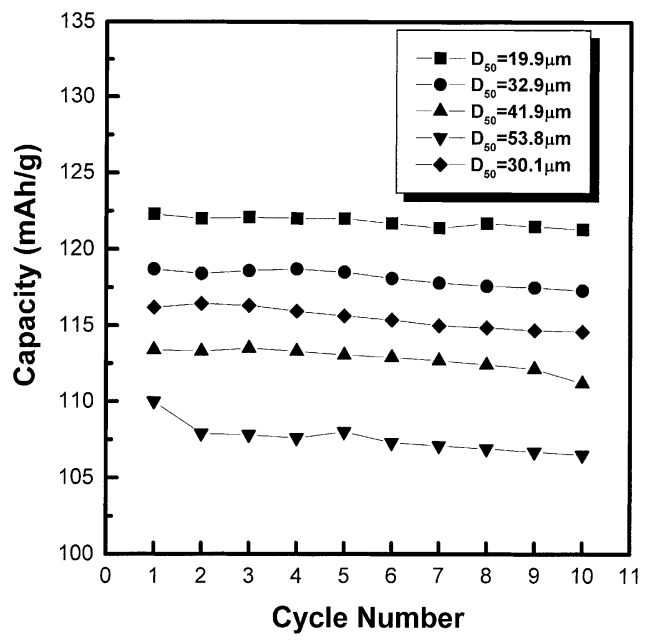

Fig. 2. Specific discharge capacity of $\mathrm{LiMn}_{2} \mathrm{O}_{4}$ powders with different particle sizes.

equilibrium between $\lambda-\mathrm{MnO}_{2}$ and $\mathrm{Li}_{0.5} \mathrm{Mn}_{2} \mathrm{O}_{4}$, while the second plateau represents a phase equilibrium between $\mathrm{Li}_{0.5} \mathrm{Mn}_{2} \mathrm{O}_{4}$ and $\mathrm{LiMn}_{2} \mathrm{O}_{4}$ [12]. As for the powders with $D_{50}=19.9 \mu \mathrm{m}$, these two plateaus seem to merge with each other, and the charge-discharge curves become continuous. The relation between the specific discharge capacity and the cycle number is plotted in Fig. 2. It is found that for the four sieved powders, the capacity significantly increases with a decrease in the average particle size. In the first cycle, the discharge capacities for the powders with $D_{50}=19.9,32.9$, 41.9 , and $53.8 \mu \mathrm{m}$ are $122.3,118.7,113.4$, and $110 \mathrm{mAh} / \mathrm{g}$, respectively. After 10 cycles, the smallest powders also exhibit the largest capacity. The unsieved powders exhibit the intermediate capacity around $116 \mathrm{mAh} / \mathrm{g}$. The capacity of the unsieved powders can be recognized as a summation of the capacities of the powders with different sizes. Based on this concept, the fraction of different powder is an important factor in affecting the capacity. The average particle size of the unsieved powders is $30.1 \mu \mathrm{m}$, however, the unsieved powders have lower capacity than the sieved powders with $D_{50}=32.9 \mu \mathrm{m}$. This is because the unsieved powders have a wide particle size distribution and a large fraction of large powders.

The coulomb efficiency of $\mathrm{LiMn}_{2} \mathrm{O}_{4}$ was also measured. This efficiency is defined as the discharge capacity divided by the charge capacity in one charge/discharge cycle. In the first cycle, the efficiency is about $92 \%$ of all specimens, indicating that a small fraction of lithium ions is incapable of intercalating back into the host structure. However, after cycling for three to four runs, the coulomb efficiency is increased to a nearly constant value. The value of coulomb efficiency also increased with a decrease in particle size. The powders with $D_{50}=19.9 \mu \mathrm{m}$ have the highest efficiency, which is around $99.8 \%$. The above result reveal that the smallest powders with $D_{50}=19.9 \mu \mathrm{m}$ exhibits the best electrochemical performance among four sieved powders. When the particle size is reduced, the overall surface area is 


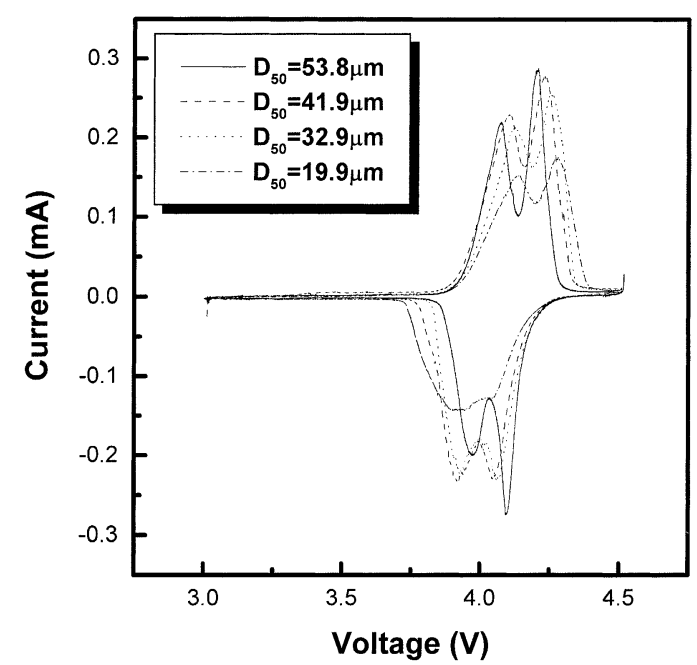

Fig. 3. Cyclic voltammetry of $\mathrm{LiMn}_{2} \mathrm{O}_{4}$ powders with different particle sizes.

increased. Thus, cathode consisting of small particles with large interface area can provide more lithium ions for diffusion, leading to the high ionic current and specific capacity. In addition, during the discharge process, small particles can provide more interfacial area for contact within the liquid electrolyte and hence can increase the opportunity for lithium ions to intercalate back into the host structure, thereby resulting in the high coulomb efficiency.

In order to further investigate the influence of particle size on the extraction/intercalation behavior of lithium ions, cyclic voltammetry analysis was performed. Fig. 3 illustrates the cyclic voltammograms for the sieved powders. All specimens display two peaks, which represent the mixed phases and different intercalation stages of lithium ions. However, during the oxidation procedure, it is found that the smaller the particle size, the higher the oxidation potential is required to perform the extraction of lithium ions. Deintercalation of lithium ions at higher potential indicates that more driving force is necessary to impel the lithium ions from the host structure to the anode. This implies that there is higher mass-transfer resistance existing in the small $\mathrm{LiMn}_{2} \mathrm{O}_{4}$ particles than in the large ones. In the cathode materials, liquid electrolyte is filled in the pores and spacious tunnels among particles. When the particle size is large, the size of pores and spacious tunnels among particles tend to become large. Since the lithium ions are easier to transport in the liquid electrolyte than in the solid particles, the large pores among large particles reduce the mass-transfer resistance of lithium ions. Therefore, the required potential for extracting lithium ions in the small particles is higher than that in the large particles. Consequently, the particle size of $\mathrm{LiMn}_{2} \mathrm{O}_{4}$ powder significantly affects its electrochemical properties. For better adjusting the charge/discharge performance in lithium-ion batteries, the particle size of $\mathrm{LiMn}_{2} \mathrm{O}_{4}$ should be well controlled by mechanical separation or synthesis processes.

\section{Conclusion}

The effects of the particle size of $\mathrm{LiMn}_{2} \mathrm{O}_{4}$ powders on the electrochemical performance in lithium ion batteries have been investigated. $\mathrm{LiMn}_{2} \mathrm{O}_{4}$ powders were sieved into different particle sizes to examine their intrinsic electrochemical characteristics. It is found that the particle size influences not only the capacity, but also the coulomb efficiency of batteries. Cathodes consisting of $\mathrm{LiMn}_{2} \mathrm{O}_{4}$ powders with the smallest particle size exhibit the largest capacity and the highest coulomb efficiency. It is believed that the small particles with large interface area provide more lithium ions for diffusion, thereby resulting in the high ionic current and specific capacity. In addition, with a decrease in particle size, the potential of the oxidation peaks during charging process become increased. It is ascribed to that the decreased opening among small $\mathrm{LiMn}_{2} \mathrm{O}_{4}$ particles increases the mass-transfer resistance and therefore, more driving force is needed to extract lithium ions from the host structure.

\section{Acknowledgements}

The authors would like to thank the National Science Council, Taiwan, the Republic of China, for financial support of this study under Contract no. NSC 89-2214E002-015.

\section{References}

[1] T. Ohzuku, M. Kitagawa, T. Hirai, J. Electrochem. Soc. 137 (1990) 769.

[2] J.M. Tarascon, D. Guyomard, J. Electrochem. Soc. 138 (1991) 2864.

[3] J.M. Tarascon, D. Guyomard, Electrochim. Acta 38 (1993) 1221.

[4] A. Momchilov, V. Manev, A. Momchilov, A. Nassalevska, A. Kozawa, J. Power Sources 41 (1993) 305.

[5] R.J. Gummow, A.de. Kock, M.M. Thackeray, Solid State Ionics 69 (1994) 59.

[6] J.M. Tarascon, E. Wang, F.K. Shokoohi, J. Electrochem. Soc. 138 (1991) 2859.

[7] W. Liu, K. Kowal, G.C. Farrington, J. Electrochem. Soc. 143 (1996) 3590 .

[8] Z. Jiang, K.M. Abraham, J. Electrochem. Soc. 143 (1996) 1591.

[9] K.T. Hwang, W.S. Um, H.S. Lee, J.K. Song, K.W. Chung, J. Power Sources 74 (1998) 169.

[10] J.H. Choy, D.H. Kim, C.W. Kwon, S.J. Hwang, Y.I. Kim, J. Power Sources 77 (1999) 1.

[11] R. Vacassy, H. Hofmann, N. Papageorgiou, M. Gratzel, J. Power Sources 81 (1999) 621.

[12] F.K. Shokoohi, J.M. Tarascon, B.J. Wilken, D. Guyomard, C.C. Chang, J. Electrochem. Soc 139 (1992) 1845. 